\title{
Elodea nuttallii: uptake, translocation and release of phosphorus
}

\author{
Susanne Angelstein ${ }^{1, *}$, Hendrik Schubert ${ }^{2}$ \\ ${ }^{1}$ UFZ-Helmholtz Centre for Environmental Research, Department of Lake Research, Brückstrasse 3a, 39114 Magdeburg, \\ Germany \\ ${ }^{2}$ University of Rostock, Biosciences, Albert-Einstein-Str. 3, 18051 Rostock, Germany
}

\begin{abstract}
Based on the wide range of Elodea nuttallii, from oligo-mesotrophic waters to highly eutrophic environments, it is important to determine its potential effect on the phosphorus cycle, particularly in nutrient-poor lake ecosystems. Therefore, the absorption, transport and release of phosphorus by E. nuttallii plants were studied using ${ }^{33} \mathrm{P}$. The experiments were conducted in a 2-compartment apparatus for translocation studies and in non-partitioned Erlenmeyer flasks for the determination of uptake kinetics. The plants absorbed phosphorus via both roots and shoots. The phosphorus uptake via shoots significantly exceeded the phosphorus uptake via roots. The absorbed phosphorus was equally translocated via acripetal or basipetal movements, and was incorporated in all parts of the plants tested. The determined phosphorus incorporation rate $\left(\mathrm{IR}_{\mathrm{P}}\right)$ was nearly 5 times lower when phosphorus was fed through the root system, than the $\mathrm{IR}_{\mathrm{P}}$ when phosphorus was fed through the shoots. Additionally, we detected clear evidence for phosphorus recycling via plants. Phosphorus recycling processes have a substantial effect on the balance of phosphorus acquisition by E. nuttallii. However, phosphorus uptake was exclusively detected during illumination. Considering this strong dependency of phosphorus uptake on light, we assume that the absorption and release of phosphorus might be linked with photosynthesis and respiratory processes. Our results suggest that the effect on lake water of a potential leakage of phosphorus via the shoots might be small.
\end{abstract}

KEY WORDS: Elodea nuttallii - Macrophyte - Phosphorus cycle in lakes · Phosphorus uptake · Phosphorus release $\cdot$ Phosphorus recycling

Resale or republication not permitted without written consent of the publisher

\section{INTRODUCTION}

In Europe, Nuttall's waterweed Elodea nuttallii (Planchon) H. St. John, 1920 is an invasive species originating from North America (Cook \& Urmi-König 1985). It often forms dense, monospecific stands and displaces other aquatic plants from many localities (Simpson 1984, 1990, Barrat-Segretain 2005). It is able to grow in turbid, highly eutrophic waters (Cook \& Urmi-König 1985, Ozimek et al. 1993, Thiébaut \& Muller 1999), as well as in clear oligo-mesotrophic waters (Thiébaut et al. 1997, Barrat-Segretain 2001, Nagasaka 2004). Its wide distribution indicates a relatively flexible ability to use different nutrient sources: water or sediment. Particularly in oligomesotrophic waters E. nuttallii has to use several nutrient sources, among which nutrient uptake via root absorption might play a major role (cf. Carignan \& Kalff 1980, Barrat-Segretain 2001, Nagasaka 2004).

Root systems of submerged hydrophytes are reduced markedly in comparison to those of their terrestrial forefathers (Agami \& Waisel 1986). This is compensated by their ability to obtain water and minerals directly through their shoots (Bristow \& Whitcombe 1971, Agami \& Waisel 1986, Madsen \& Cedergreen 2002). Robach et al. (1995) and Madsen \& Cedergreen (2002) have shown that leaf uptake can become the main source for phosphorus in E. nuttallii and $E$. canadensis, respectively. In contrast, several studies have indicated that aquatic macrophytes rely mainly on the sediment for their phosphorus supply (Bole \& Allan 1978, Carignan \& Kalff 1980, Chen \& Barko 1988, 
Pelton et al. 1998). There is also evidence that the rapid growth of several aquatic plants, including Elodea sp., normally requires the presence of a root system growing within a nutrient-rich substrate (Peltier \& Welch 1969, Bristow \& Whitcombe 1971, Xie et al. 2007). Most of the conflicting results in general might be based on the ability of aquatic vascular plants to adapt their phosphorus uptake to the sources available-whether present in the water or in the sediment-with respect to the surrounding phosphorus concentration and the biochemical availability of phosphorus (McRoy \& Barsdate 1970, Denny 1972, Bole \& Allan 1978, Shardendu \& Ambasht 1991).

However, the potential leakage of absorbed phosphorus via foliage or roots has been discussed controversially by several authors. McRoy \& Barsdate (1970) reported a rapid phosphorus absorption by both roots and shoots of Zostera marina. The absorbed phosphorus was transported and subsequently excreted through the untreated part. Also, Gentner (1977) came to similar conclusions for Valisneria spiralis, whilst Bristow \& Whitcombe (1971) and Welsh \& Denny (1979) found considerable root to shoot transport in Elodea sp. and Myriophyllum sp. with no excretion. DeMarte \& Hartman (1974) also measured a rapid shoot to root transport in Potamogeton sp., whereas Bristow \& Whitcombe (1971) did not find this. Moreover, Eugelink (1998) found no significant phosphorus release of E. nuttallii and E. canadensis, but his experimental treatments also disregarded the evidential major influences of temperature, light, potential recycling of released P, etc. (e.g. Ingold 1936, Jeschke \& Simonis 1965, McRoy \& Barsdate 1970).

In such cases, at least mass developments of aquatic plants like Elodea nuttallii may play an important role in the phosphorus cycle of lake ecosystems (e.g. DeMarte \& Hartman 1974, Ozimek et al. 1993). Particularly with regards to a dominant phosphorus uptake from sediment, roots reduce the phosphorus content in the surrounding pore water (Chen \& Barko 1988, Laskov et al. 2007) and transport it to the surface, where it may be released into the water via leakage from the plant, grazer recycling, or decomposition (McRoy \& Barsdate 1970, DeMarte \& Hartman 1974, Carignan \& Kalff 1980). With respect to several contradicting results presented in the literature (cf. McRoy \& Barsdate 1970, Welsh \& Denny 1979), it is essential to quantify the potential phosphorus leakage via roots or shoots in order to estimate its relevance for the nutrient balance of lake ecosystems.

Therefore, the present study was designed to critically investigate the preferred way of phosphorus absorption (via shoots or roots), translocation of phosphorus and potential phosphorus release via shoots or roots in Elodea nuttallii. We paid particular attention to the possibility of leakage through the seals, potential day-night influences and phosphorus re-absorption via E. nuttallii plants.

\section{MATERIALS AND METHODS}

Plant material was collected under an ice cover in February 2006 in a large mining lake in Germany (Goitschesee; $51^{\circ} 37^{\prime} \mathrm{N}, 12^{\circ} 24^{\prime} \mathrm{E}$ ). Plants were transported immediately to the laboratory, and shoot tips (length ca. 10 to $15 \mathrm{~cm}$ ) were planted in aerated aquaria $(50 \times 30 \times 30 \mathrm{~cm})$ containing ca. $5 \mathrm{~cm}$ of nutrient-rich, littoral sediment (with total phosphorus [TP, mean \pm $\mathrm{SD}]=0.058 \pm 0.01 \mathrm{mg} \mathrm{g}^{-1}$ ) at room temperature. The aquaria were filled with lake water $(\mathrm{pH} 8.1 ; 1143 \mu \mathrm{S}$ $\mathrm{cm}^{-1}$ ), which was replaced every $2 \mathrm{wk}$. The chemical characteristics of the lake water are shown in Table 1. Irradiance (Osram FQ 80 W/865, Lumilux Plus Daylight; 140 to $160 \mu \mathrm{mol}$ photons $\mathrm{m}^{-2} \mathrm{~s}^{-1}$ incident irradiance) was provided in a 10:14 $\mathrm{h}$ dark:light cycle. The irradiance (photosynthetically active radiation, PAR) was measured with a LI-250 PAR-meter (LI-COR), equipped with a spherical underwater quantum sensor (US-SQS/L, Walz).

To reduce the incorporated phosphorus reservoir, plants (1.6 $\mathrm{g} \mathrm{P} \mathrm{kg}^{-1}$ dry weight [DW]) were acclimated before measurements for $20 \mathrm{~d}$ with intact roots and shoots in aerated aquaria $(40 \times 25 \times 25 \mathrm{~cm})$ at room temperature (moderate 18 to $20^{\circ} \mathrm{C}$ ) containing ca. $5 \mathrm{~cm}$

Table 1. Chemical characteristics of the lake water (Goitschesee in Germany), at the sampling station. All data are means \pm SD of 7 samples from December 2006 to November 2007. DOC: dissolved organic carbon; TIC: total inorganic carbon; TOC: total organic carbon; SRP: soluble reactive phosphorus; TP: total phosphorus

\begin{tabular}{|lc|}
\hline Component & Content $\left(\mathrm{mg} \mathrm{l}^{-1}\right)$ \\
\hline $\mathrm{Cl}^{-}$ & $37.76 \pm 1.35$ \\
$\left(\mathrm{SO}_{4}\right)^{2-}$ & $296.61 \pm 15.39$ \\
$\mathrm{Ca}^{2+}$ & $11.14 \pm 4.85$ \\
$\mathrm{~K}^{+}$ & $7.93 \pm 0.76$ \\
$\mathrm{Mg}^{2+}$ & $15.01 \pm 1.61$ \\
$\mathrm{Na}^{+}$ & $27.09 \pm 1.85$ \\
$\mathrm{DOC}$ & $4.4 \pm 0.16$ \\
$\mathrm{TIC}$ & $10.56 \pm 0.83$ \\
$\mathrm{TOC}$ & $4.41 \pm 0.13$ \\
$\mathrm{NH}_{4}{ }^{+}$ & $0.034 \pm 0.025$ \\
$\mathrm{NO}_{2}{ }^{-}$ & $0.01 \pm 0.006$ \\
$\mathrm{NO}_{3}{ }^{-}$ & $1.7 \pm 0.13$ \\
$\mathrm{Si}$ & $0.79 \pm 0.17$ \\
$\mathrm{SRP}$ & $<0.003$ \\
$\mathrm{TP}$ & $<0.006$ \\
$\mathrm{Al}$ & $<0.1$ \\
$\mathrm{Fe}$ & $0.013 \pm 0.006$ \\
$\mathrm{Mn}$ & $0.03 \pm 0.018$ \\
\hline
\end{tabular}


autoclaved silicate sand and $25 \mathrm{~cm}$ autoclaved nutrient-poor lake water (0.006 g P l${ }^{-1} ; \mathrm{pH}$ 8.9). Irradiance (Osram Halolux Classic A, $60 \mathrm{~W}$; PAR: 40 to $50 \mu \mathrm{mol}$ photons $\mathrm{m}^{-2} \mathrm{~s}^{-1}$ on the water surface) was provided in a 12:12 h dark:light cycle. The aquaria were cleaned, and the lake water was changed weekly. After acclimatisation the average phosphorus reservoir of Elodea nuttallii was ca. $0.86 \mathrm{~g} \mathrm{P} \mathrm{kg}^{-1} \mathrm{DW}$.

Long-term experiment. To analyze the acripetal and basipetal phosphorus translocation mechanisms of Elodea nuttallii, 2 experiments were carried out between the end of November 2006 (basipetal) and beginning of March 2007 (acripetal), each with 6 replicates and 3 controls. A modified 2-compartment apparatus, modelled according to Frank \& Hodgson (1964) and Bristow \& Whitcombe (1971), was used for both ${ }^{33} \mathrm{P}$ translocation experiments (Fig. 1). The leaves of each plant (stem length ca. $10 \pm 1 \mathrm{~cm}$ ) were removed ca. 1 to $1.5 \mathrm{~cm}$ from an appropriate section in the middle of the stem, which was wrapped in an eversible plug. The plug was upended over a powder funnel neck, and potential permeable scopes at proximate osculation points were isolated generously by a watertight silicon-free vacuum crease, called glisseal ${ }^{\circledR} \mathrm{N}$. The funnel neck was then fitted into the neck of a 100 ml wide-mouth Erlenmeyer flask. In order to reduce evaporation effects, a glass Petri dish was used as a lid on top of the upper compartment, after it was filled with media. The 2 compartments were stabilised using an ebonite ring. Roots were only allowed to grow in the lower compartment. In order to exclude light from the root zone, the lower compartment was covered with

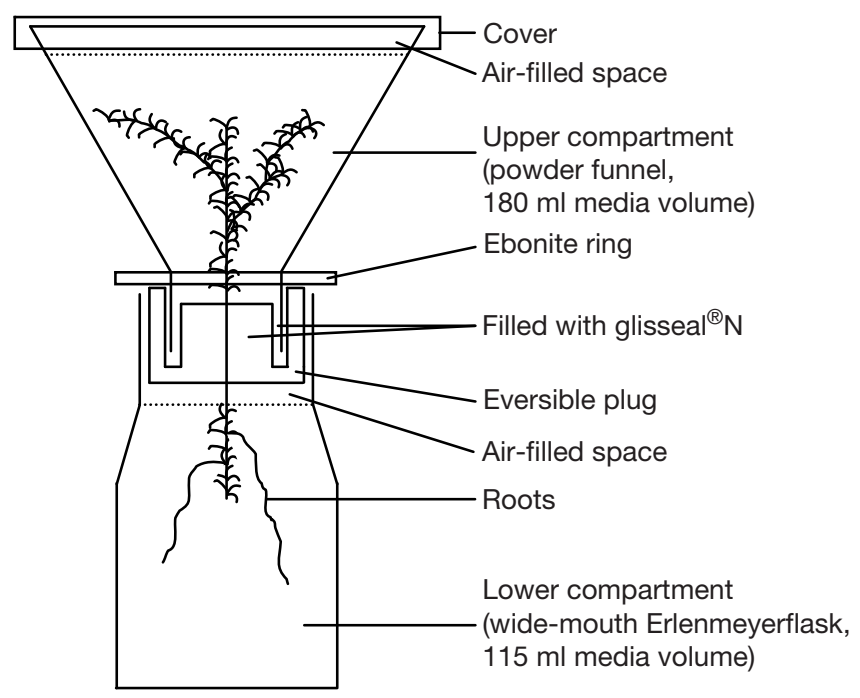

Fig. 1. Two-compartment apparatus used in the long-term experiments for measurements of ${ }^{33} \mathrm{P}$ translocation in Elodea nuttallii plants. By means of a thin tube, plants were carefully threaded into the plug. Each compartment was equally filled with radioactive or non-radioactive medium metal foil. Temperature and light conditions were maintained under the same conditions as in the acclimatisation culture. The controls were treated equally, whereas plants were imitated by $5 \mathrm{~cm}$ long plastic sticks.

To investigate acripetal phosphorus translocation, the upper segment (180 ml medium volume) of the 2-compartment apparatus was filled with autoclaved lake water, here used as phosphorus-depleted medium $\left(0.006 \mathrm{~g} \mathrm{P} \mathrm{l}^{-1}\right)$, and the lower segment $(115 \mathrm{ml}$ medium volume) was filled with ${ }^{33} \mathrm{P}$-medium $\left(0.150 \mathrm{~g} \mathrm{P} \mathrm{l}^{-1}\right.$; $\mathrm{pH}$ 8.4). For the basipetal phosphorus translocation experiment, the compartments were filled vice versa. The ${ }^{33} \mathrm{P}$-medium used was a composition of autoclaved lake water and $1 \mathrm{ml} \mathrm{l}^{-1}$ of a ${ }^{33} \mathrm{P}$ stock solution $(0.66 \mathrm{~g}$ $\mathrm{KH}_{2} \mathrm{PO}_{4} \mathrm{l}^{-1} ; \mathrm{pH} 5$ ). The radionuclide ${ }^{33} \mathrm{P}$, obtained from GE Healthcare as orthophosphate in dilute $\mathrm{HCl}$ solution, had been added to the stock solution before the experiment was started.

The activity of all samples was counted using a liquid scintillation analyser (LSA, Packard Tri-Carb 2300TR). Phosphorus-depleted media were counted for $10 \mathrm{~d}$ and then changed every $24 \mathrm{~h} .{ }^{33} \mathrm{P}$-media were counted at the beginning of the measurements, as well as at the end of the experiment. Measured counts of the media were corrected for radioisotope decay. Because of coeval measurements of the controls, background correction was negligible.

Afterwards, plants were harvested, agitated 3 times thoroughly in deionised water for about $10 \mathrm{~s}$ and towelled with lint-free paper. Immediately afterwards, fresh weights (FW) of whole plants were determined. Subsequently, samples of leaves, stems and roots of each contaminated plant and 3 uncontaminated control plants were separated and FW was measured again. Separated plant samples were digested by incubation in $2 \mathrm{ml}$ Soluene 350 for $72 \mathrm{~h}$ and counted afterwards. Measured counts were corrected for radioisotope decay. Because of coeval measurements of uncontaminated control plants, correction of background was also negligible.

Several LSA cocktails were used for counts per minute (cpm) determinations. Plant samples were measured using Ultima Gold F, and both media were measured using Ultima Gold XR.

The maximal phosphorus incorporation rate $\left(\mathrm{IR}_{\mathrm{P}}\right)$ for whole plants was calculated using:

$$
\mathrm{IR}_{\mathrm{P}}\left(\mu \mathrm{gP} \mathrm{kg} \mathrm{kW} \mathrm{d}^{-1}\right)=\frac{D_{\mathrm{P}}-I_{\mathrm{P}}}{\mathrm{FW}_{t} \cdot t}
$$

where $D_{\mathrm{P}}$ and $I_{\mathrm{P}}$ are phosphorus decrease or increase in cultivation solution, respectively, calculated from the measured changes in radioactivity $\left({ }^{33} \mathrm{P}\right)$ after incubation time $(t)$ in days. $\mathrm{FW}_{t}$ is plant fresh weight at $t$. The $I_{\mathrm{P}}$ values for plant parts (leaves, stem and roots) 
were calculated from the measured activity distribution within the plant at $t$.

Short-term experiment. In order to investigate the day-night influences of the phosphorus translocation, as well as phosphorus translocation mechanisms without the influence of a 2-compartment apparatus (at bidirectional phosphorus translocation) for the whole plant, a short-term experiment (phosphorus uptake period of 3 d) was carried out in March 2007. The setup and measurements were similar to those described above for long-term determinations. However, in place of the 2-compartment apparatus, plants were retained in a $100 \mathrm{ml}$ wide-mouth Erlenmeyer flask, filled with $115 \mathrm{ml}{ }^{33} \mathrm{P}$ medium. In contrast to long-term determinations, for a more sensitive yield of counts, the ${ }^{33} \mathrm{P}$ medium contained twice as much of the radioisotope. Samples were taken after $0,6,12,24,30,36,48,54,60$ and $72 \mathrm{~h}$.

Statistical analysis. For each experiment, control data and original data, as well as replicates, were compared using ANOVA $(\mathrm{p}<0.05)$. For the short-term experiment, the effects of light were tested using the paired $t$-test $(\mathrm{p}<0.05)$.

\section{RESULTS}

\section{Long-term experiment}

The translocation and accumulation of ${ }^{33} \mathrm{P}$ in Elodea nuttallii plants were measured over a $10 \mathrm{~d}$ period. Figs. $2 \& 3$ show the result of the long-term experiment in which ${ }^{33} \mathrm{P}$ was first fed through the root system (Fig. 2) and then fed through the shoot (Fig. 3). The chosen phosphorus concentration of the ${ }^{33} \mathrm{P}$ medium was set at a high concentration $\left(150 \mu \mathrm{g} \mathrm{P}^{-1}\right)$ in order to obtain definite saturation. Our observation of healthy plant growth is in good agreement with the results of others (cf. Bole \& Allan 1978, Carignan \& Kalff 1980). ${ }^{33} \mathrm{P}$ was translocated within the plants from rooted stem bases to the upper plant parts (foliage and stem; Fig. 2) and vice versa (Fig. 3). The $\mathrm{IR}_{\mathrm{P}}$ and the distribution of $\mathrm{IR}_{\mathrm{P}}$ within these plants are depicted in Table 2 . The absorption of phosphorus by shoots significantly exceeded the phosphorus absorption by the root system. In detail, the mean phosphorus absorption by the shoots $\left(73.7 \%\right.$ from primary ${ }^{33} \mathrm{P}$ solution), which was measured if phosphorus was added to the upper compartments, was $>2$-fold higher than phosphorus absorption by the roots (31.1\%), which was measured if phosphorus was added to the lower compartment (Figs. 2B \& 3A). These different kinds of uptake rates in the shoot and the root system were also reflected by the different characteristics of the $\operatorname{IR}_{\mathrm{P}}$ (cf. Table 2), where, in the course of the low phosphorus absorption
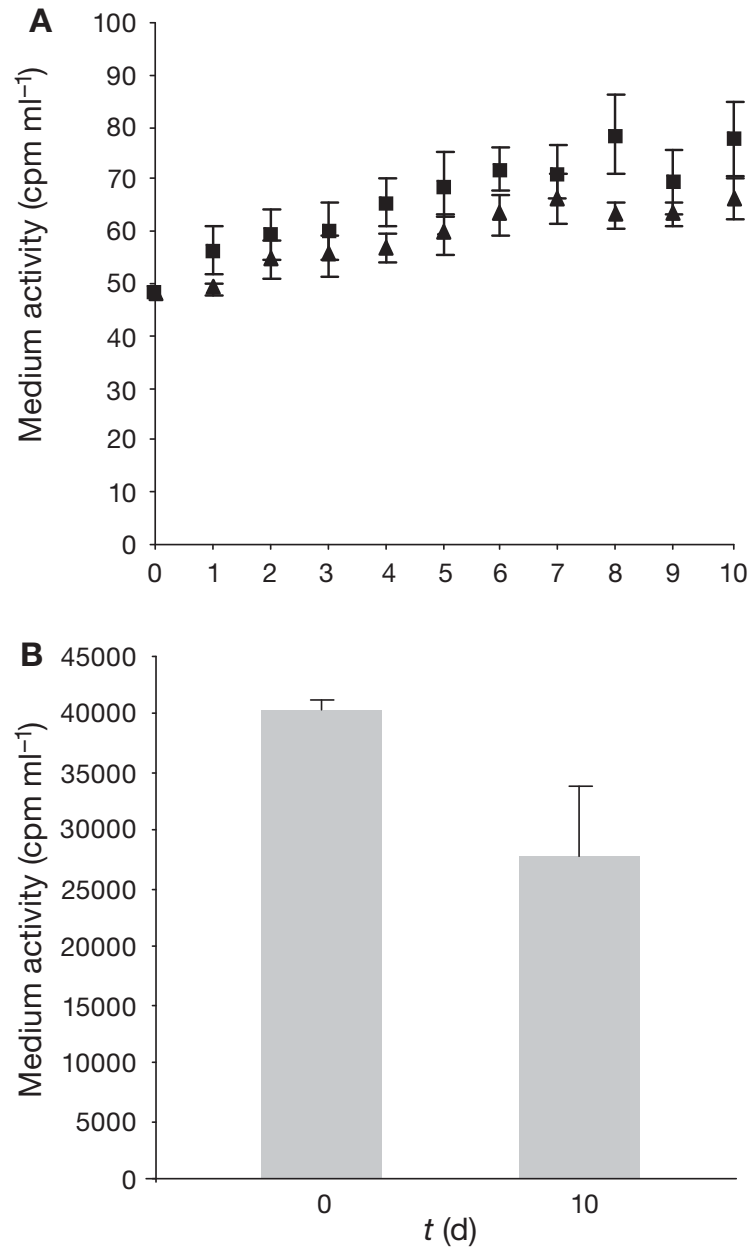

Fig. 2. Elodea nuttallii. Uptake and release of phosphorus $\left({ }^{33} \mathrm{P}\right)$ fed through the root system, represented as changes in medium activity (cpm: counts per minute). (B) ${ }^{33} \mathrm{P}$ uptake by roots and $(\mathrm{A}){ }^{33} \mathrm{P}$ release by upper plant parts (foliage and stem, -) (see 'Materials and methods; Long-term experiments'). All data are mean $\pm \mathrm{SD}(\mathrm{n}=6)$; in $(\mathrm{A})$ mean values of control experiments $(\boldsymbol{\Lambda}, \mathrm{n}=3)$ are also shown. $t$ : incubation time

by roots, only a mean of $4.5 \mu \mathrm{g} \mathrm{P} \mathrm{kg}^{-1} \mathrm{FW} \mathrm{d}^{-1}$ was incorporated instead of $21.7 \mu \mathrm{g} \mathrm{P} \mathrm{kg}^{-1} \mathrm{FW} \mathrm{d}^{-1}$ if basipetal phosphorus movements were analysed. However, in spite of the comparatively low $\mathrm{IR}_{\mathrm{P}}$ based on a low phosphorus absorption rate by the roots, an average of $13.8 \%$ of the absorbed phosphorus was displaced in the upper plant compartments: foliage and stem (cf. Table 2). In contrast, whilst basipetal transport was observed, only $4.6 \%$ of the absorbed phosphorus from the upper plant compartments was transferred and incorporated into the roots.

After $7 \mathrm{~d}$ of incubation during investigation of basipetal phosphorus movements in Elodea nuttallii plants, there was evidence of ${ }^{33} \mathrm{P}$ release in the lower compartment via the roots, based on a significant activity increase in the lower compartment (Fig. 3B). As shown in 

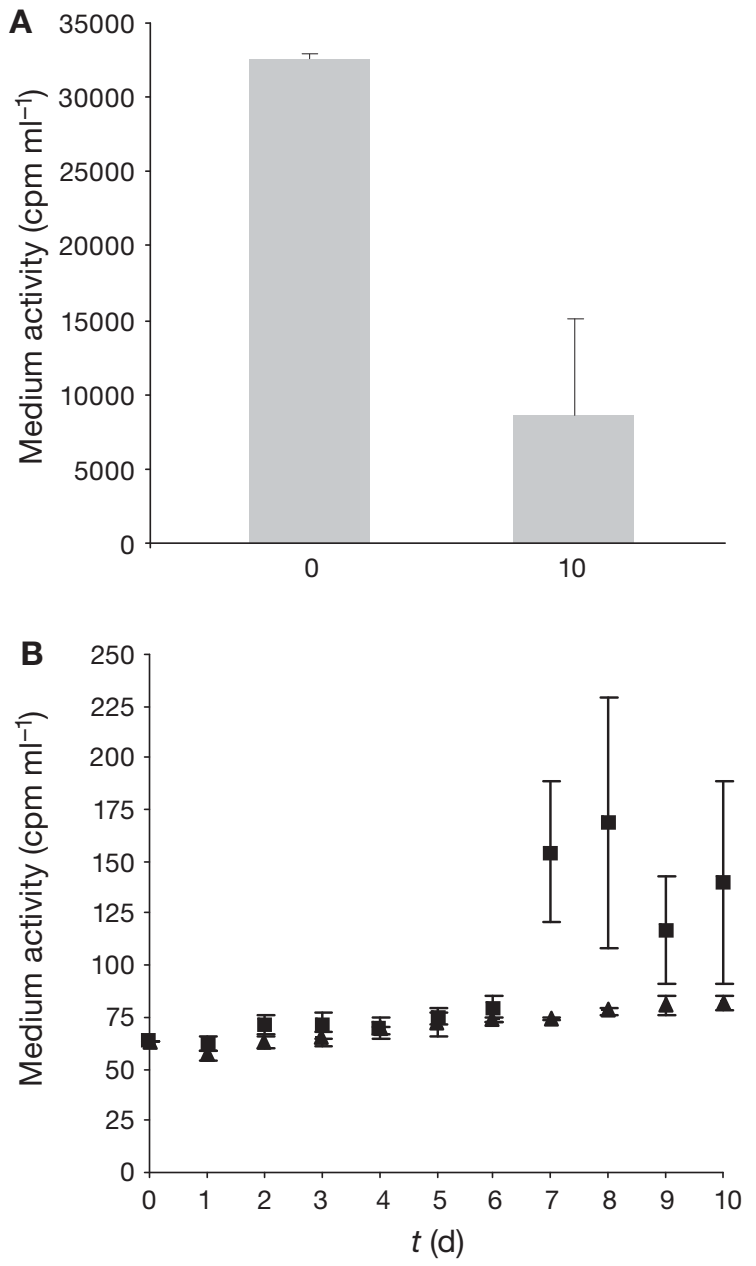

Fig. 3. Elodea nuttallii. Uptake and release of phosphorus $\left({ }^{33} \mathrm{P}\right)$ fed through the shoots, represented as changes in medium activity (cpm ml $\mathrm{m}^{-1}$ ): (A) ${ }^{33} \mathrm{P}$ uptake by foliage and stem and (B) ${ }^{33} \mathrm{P}$ release by lower plant parts (roots, (see 'Materials and methods; Long-term experiment'). All data are mean $\pm \mathrm{SD}(\mathrm{n}=6)$; in $(\mathrm{B})$ mean values of control experiments $(\boldsymbol{\Lambda}, \mathrm{n}=3)$ are also shown

Fig. 2A, there was no significant phosphorus excretion by the upper plant compartments if acripetal phosphorus translocation was observed. The apparent small increase in solution activity in both controls (cf. Figs. 2A \& $3 \mathrm{~B})$ and the non-radioactive medium of the upper compartment (Fig. 2A) can be traced back to the standardized correction of the radioisotope decay.

\section{Short-term experiment}

The absorption and release of ${ }^{33} \mathrm{P}$ by Elodea nuttallii plants incubated in radioactive medium over a $3 \mathrm{~d}$ period and the dependency of phos-

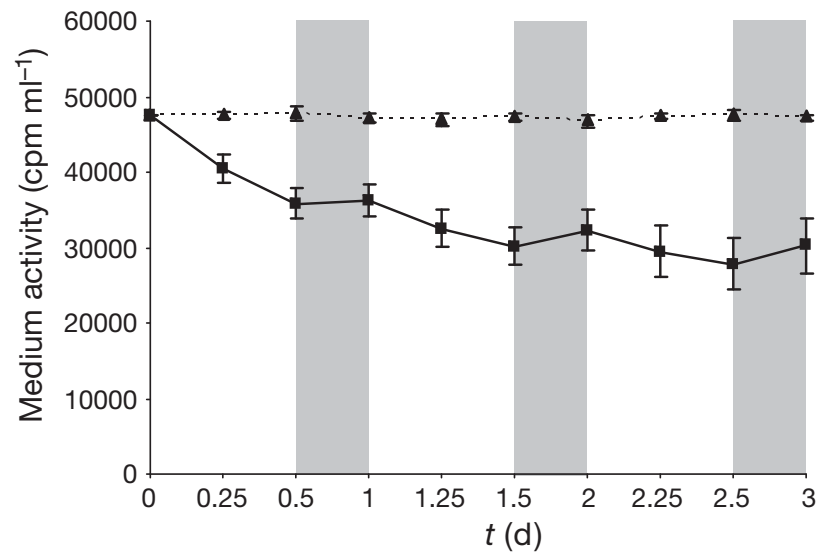

Fig. 4. Elodea nuttallii. Absorption and release of ${ }^{33} \mathrm{P}$ in plants and the ${ }^{33} \mathrm{P}$ movement dependency on light as observed by the decrease or increase of radioactivity in cultivation solution (a) (see 'Materials and methods; Short-term experiment'). Dark periods are indicated by grey bars. All data are mean \pm $\mathrm{SD}(\mathrm{n}=6)$; mean values of control experiments $(\boldsymbol{\Lambda}, \mathrm{n}=3)$ are also shown

phorus absorption and release on illumination are illustrated in Fig. 4. To exclude possible effects of a 2-compartment apparatus, E. nuttallii was incubated in wide-mouth Erlenmeyer flasks. The data presented clarify the strong dependency of phosphorus uptake by E. nuttallii plants on illumination. Specifically, the phosphorus uptake could exclusively be detected during the daytime, when the light was on. During this time, E. nuttallii consumed ca. $36 \%$ of the offered phosphorus from the primary ${ }^{33} \mathrm{P}$ solution (Fig. 4). Moreover, it was possible to determine a significant phosphorus release over the second and third dark periods (between 36 and $48 \mathrm{~h}$ and between 60 and $72 \mathrm{~h}$, respectively), whereas the determined phosphorus uptake per day decreased rapidly in time. The behaviour of the average phosphorus uptake rate $\left(\mu \mathrm{g} \mathrm{P} \mathrm{mg}^{-1} \mathrm{FW} \mathrm{d}^{-1}\right.$ ) of E. nuttallii over time could be described by the following equation: $y=$ $0.0182 \operatorname{Ln}(x)+0.0553$, with $r^{2}=0.8484$. As can be seen in Fig. 4, the activity in the control solutions was relatively constant over the whole time period. In comparison to the long-term experiments, lower differences in medium activity can be reduced to the standardized correction of radioisotope decay.

Table 2. Elodea nuttallii. Maximal $\mathrm{P}$ incorporation rate $\left(\mathrm{IR}_{\mathrm{P}}, \mu \mathrm{g} \mathrm{P} \mathrm{kg}^{-1} \mathrm{FW} \mathrm{d}^{-1}\right.$; FW: fresh weight) of plants, which were incubated for 3 or $10 \mathrm{~d}$ in an Erlenmeyer flask or a 2-compartment apparatus. The calculation of $I_{P}$ is given in 'Results'. All data are mean \pm SD $(n=6)$

\begin{tabular}{|lrrrrr|}
\hline $\begin{array}{l}\text { Investigated } \\
\text { translocation }\end{array}$ & $\begin{array}{c}\text { Incubation } \\
\text { (d) }\end{array}$ & Plant & Leaf & Stem & Root \\
\hline Acripetal & 10 & $4.5 \pm 0.92$ & $0.36 \pm 0.61$ & $0.26 \pm 0.32$ & $3.88 \pm 0.97$ \\
Basipetal & 10 & $21.7 \pm 5.15$ & $13.19 \pm 3.21$ & $7.51 \pm 2.35$ & $1.0 \pm 0.61$ \\
Bidirectional & 3 & $22.31 \pm 3.46$ & $13.94 \pm 2.62$ & $6.34 \pm 2.88$ & $2.04 \pm 1.18$ \\
\hline
\end{tabular}


The $I R_{P}$ and the distribution of $\mathrm{IR}_{\mathrm{P}}$ within the plants are depicted in Table 2. The $\mathrm{IR}_{\mathrm{P}}$ of plants incubated for $3 \mathrm{~d}$ in Erlenmeyer flasks show analogous values to plants incubated for $10 \mathrm{~d}$ in the 2-compartment apparatus to determine their basipetal phosphorus movement (Table 2), especially with regard to the distribution of phosphorus within the plants. Under both conditions $>60 \%$ of absorbed phosphorus was incorporated in foliage and ca. 28 or $34 \%$ of absorbed phosphorus was incorporated in stems. Contrary results were determined for the $\mathrm{IR}_{\mathrm{P}}$ at acripetal phosphorus movements. During the investigation of basipetal and bidirectional phosphorus movements, plants were able to incorporate almost 5 times more phosphorus than during the examination of acripetal phosphorus movements. Moreover, with regards to the phosphorus distribution within the plants, there was a clear shifting in the ratio of shoots (leaves and stem) versus roots of incorporated phosphorus from ca. 1:6.2 for acripetal phosphorus movements to ca. 20:1 and 10:1 for basipetal and bidirectional phosphorus movements, respectively (Table 2).

\section{DISCUSSION}

Rooted aquatic vascular plants are able to adapt their phosphorus uptake strategy to the sources available and relocate the absorbed phosphorus in several directions: from the shoots into the roots and vice versa (cf. Bristow \& Whitcombe 1971, DeMarte \& Hartman 1974, Pelton et al. 1998). Moreover, several authors have clearly described the dependency of phosphorus uptake efficiency on the phosphorus content of the surrounding water (cf. Granéli \& Solander 1988, Shardendu \& Ambasht 1991, Robach et al. 1995, Pelton et al. 1998). Based on this it was possible for Bole \& Allan (1978) to show that in nutrient-rich water (sedi-

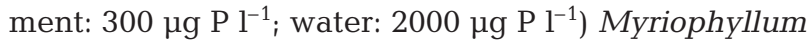
spicatum plants were able to satisfy their phosphorus requirement almost exclusively via shoot absorption (averaged 92\%). Carignan \& Kalff (1980) showed for the same species that, if sediment soluble reactive phosphorus (SRP) content is high (1200 or $169 \mathrm{\mu g} \mathrm{l}^{-1}$ ) and SRP content in overlying water is low (1.9 or $0.5 \mu \mathrm{g}$ $\mathrm{P}^{-1}$ ), root absorption of $M$. spicatum plants becomes the main source of phosphorus uptake (nearly 100\%).

The 3 different experimental procedures (the examination of basipetal, acripetal and bidirectional phosphorus movements) present in the current study should clearly illustrate the ability of Elodea nuttallii plants to adapt their phosphorus uptake strategy to the availability of different kinds of phosphorus sources in a similar way (cf. Bole \& Allan 1978, Carignan \& Kalff 1980). Additionally, the presented data strongly suggest that there are large differences between the phosphorus absorp- tion kinetics of roots and shoots. The phosphorus uptake rate by shoots of $E$. nuttallii plants exceeded that by their roots almost 2-fold (Figs. 2B \& 3A). Additionally, with references to $\mathrm{IR}_{\mathrm{P}}$, phosphorus incorporation due to phosphorus absorption by shoots exceeded the phosphorus incorporation after phosphorus uptake by roots almost 5 -fold (Table 2). These results are in contrast with those published by Eugelink (1998) for E. nuttallii, who described a higher phosphorus absorption rate for the roots. This difference might be caused by difficulties with the quantification of the phosphorus budget in plants, based on the capability of phosphorus re-absorption, as a function of phosphorus absorption and release (see below). However, several authors, including Eugelink (1998; for E. canadensis), Ozimek et al. (1993; for E. nuttallii and E. canadensis) and Robach et al. (1995; for E. nuttallii and E. canadensis) have described a higher efficiency in phosphorus absorption by shoot uptake compared to that by roots for various Elodea species.

According to the phosphorus uptake rate determined (Figs. 2B \& 3A), the $\mathrm{IR}_{\mathrm{P}}$ for whole plants was highest in the case of phosphorus absorption via the shoot, whereas the distributions of phosphorus within the plants were actually the same in the case of both phosphorus uptake by shoots (2-compartment apparatus) and over the whole plant, when plants were incubated in Erlenmeyer flasks (Table 2). Moreover, if phosphorus translocation in an acripetal direction was observed, ca. $13.8 \%$ of the absorbed phosphorus was transported via roots into the shoots instead of ca. $4.6 \%$ vice versa. Therefore, even though lower phosphorus absorption via the root system was detected, substantially faster phosphorus relocation could be seen in the case of acripetal phosphorus translocation compared to basipetal phosphorus translocation.

A significant phosphorus release by the plants was detected in 2 of the 3 experiments: (1) during our investigation of the basipetal phosphorus translocation there was evidence for a release of phosphorus by the roots after $7 \mathrm{~d}$ of incubation (Fig. 3B) and (2) within the short-term (bidirectional) experiment we observed a phosphorus release that was already significant after 48 h (Fig. 4). These results are comparable with results presented by other authors, who previously postulated a net phosphorus leakage from aquatic vascular plants (McRoy \& Barsdate 1970, DeMarte \& Hartman 1974, Twilley et al. 1977).

However, if measurements were processed in a day-night cycle during the short-term experiment, the phosphorus uptake could exclusively be detected in the daytime if the light was on. This observation clarifies a strong dependency of the phosphorus uptake by Elodea nuttallii plants on illumination. Therefore, it can be assumed that the uptake and release (see below) of phosphorus in E. nuttallii plants might be linked with photosynthesis and respiratory processes 
as well and need further investigation. This finding is in good agreement with the very early results of Ingold (1936), who demonstrated a considerable influence of light on the absorption of salts by E. canadensis. A similar light dependency of phosphorus uptake by aquatic vascular plants was also shown by McRoy \& Barsdate (1970) and Jeschke \& Simonis (1965).

Based on our finding of a significant release of phosphorus by the Elodea nuttallii plants, the experiments also provided evidence for phosphorus re-absorption. In detail, the presented results demonstrate clearly that all of the released phosphorus was completely recycled by E. nuttallii plants via subsequent phosphorus reabsorption during illumination within approximately $6 \mathrm{~h}$ (Fig. 4). This highlights the substantial effect of phosphorus recycling processes on the balance of phosphorus acquisition by E. nuttallii. In particular, with regards to the strong dependency determined of phosphorus uptake on light, there is a necessity to perform quantifications of phosphorus uptake and phosphorus release directed more specifically towards potential phosphorus reabsorption and the irradiance regime. Therefore, with regards to a potential high phosphorus re-absorption by shoots, it is possible that the absence of evidence for significant phosphorus release by the shoots, in the experiments presented here, does not mean that there is no release at all. Moreover, such difficulties might be the reason why Eugelink (1998) could not find significant evidence for phosphorus release by upper or lower plant parts in E. nuttallii and E. canadensis.

Nevertheless, there was no significant phosphorus release via shoots or roots, during the first $6 \mathrm{~d}$ of examination, within the long-term experiment. This lack of significant phosphorus release could be a result of the pre-experimental acclimatisation of the culture plants in a nutrient-poor solution. This means that, even though the plant tissue of culture plants had a phosphorus content of $0.16 \% \mathrm{DW}$, which is clearly above the critical threshold for maximum yield $(0.13 \%)$ of aquatic vascular plants (see Gerloff \& Krombholz 1966), post-acclimated plants had a tissue phosphorus content of $0.086 \%$, which clearly falls below the critical value for maximum yield. Therefore, it is possible that, with longer experimental terms, the phosphorus content in plant tissue increases up to a limit where phosphorus release could be detected. This could clarify the observed phosphorus release after $7 \mathrm{~d}$ by roots when basipetal phosphorus movements were examined. Additionally, it can be considered that the absence of significant phosphorus release via shoots during the investigation of acripetal phosphorus movements was a consequence of the pre-experimental phosphorus depletion in plant tissue as well. With regards to the slower phosphorus uptake rate by roots in comparison to shoots, it appears logical that phosphorus content in plant tissue increases more slowly to a point where phosphorus release is clearly detectable.

Moreover, there are reports of phosphorus release during phosphorus uptake experiments if tissue phosphorus content of aquatic vascular plants was not depleted before the start of the experiment (cf. Gessner \& Kaukal 1952). It appears to be logical that phosphorus uptake or release depends on the phosphorus concentration in the plant tissues themselves. In accordance to this concept, our results also describe a continuously decreasing phosphorus uptake rate with time, which simultaneously correlates with an increase in phosphorus release (see short-term experiment; Fig. 4). This observation and the determination of significant phosphorus release, which was detected in the lower compartment during our investigations of basipetal phosphorus translocation, might be a result of the dependency of phosphorus uptake and phosphorus release from the phosphorus concentrations in the water, the sediments and the plant tissues.

\section{CONCLUSIONS}

Based on the results of the present study, it can be considered that the phosphorus absorption via shoots is the preferred route of phosphorus uptake for Elodea nuttallii plants. Therefore, in eutrophic lakes, phosphorus uptake via shoots is expected to dominate and should be sufficient for E. nuttallii plants to meet their phosphorus requirements. Under such conditions the plants reduce the phosphorus content in the surrounding water and, if possible, they transport the phosphorus into the sediment via release from the roots and therefore change the phosphorus content of pore water. In contrast, in oligomesotrophic lakes, E. nuttallii plants have to meet their phosphorus requirement by phosphorus absorption from sediment via roots. The slower uptake rate of roots in comparison to the faster absorption via shoots might be sufficient to meet the phosphorus requirement of a whole E. nuttallii plant under these environmental conditions. However, if phosphorus uptake from the sediment dominates, roots reduce the phosphorus content in the surrounding pore water. There was no evidence for any effect of the living plant on the overlying water via phosphorus release by the shoots. It is possible that, if phosphorus were absorbed via the shoots, it could be released again at senescence of the plants. However, with regard to the high absorption capacity of their shoots, the effect on lake water by a potential leakage of phosphorus via shoots might be negligible. Only the release into the water via grazing or decomposition might have an effect on phosphorus cycling (Thiébaut et al. 1997, Nino et al. 2005). However, the clearly illustrated ability of $E$. nuttallii plants to absorb high quantities of phosphorus by their shoots, if phosphorus supply is sufficient, pre- 
destines them for their use in phosphorus removal from waste water treatments, as has already been proposed for several macrophytes (cf. DeBusk et al. 1995, Hadad \& Maine 2007).

To gain more insight into the ecophysiology of these interesting organisms, future work should focus on questions that have not yet been covered by the present study: (1) What effect does the phosphorus release via roots have on the chemical composition of the sediment or on co-residing species? (2) What relation exists between phosphorus uptake or phosphorus release and photosynthesis or respiration? (3) Is it possible to substantiate these laboratory results by field studies?

Acknowledgements. W. v. Tümpling is acknowledged for technical support with some experiments. We are grateful to W. Geller, M. Koschorreck, E. Spijkerman and J. Tittel for helpful discussions. The authors also thank K. Rahn for technical services and S. Halbedel for critical reading.

\section{LITERATURE CITED}

Agami M, Waisel Y (1986) The ecophysiology of roots of submerged vascular plants. Physiol Veg 24:607-624

Barrat-Segretain MH (2001) Invasive species in the Rhône River floodplain (France): replacement of Elodea canadensis Michaux by E. nuttallii St. John in two former river channels. Arch Hydrobiol 152:237-251

Barrat-Segretain MH (2005) Competition between invasive and indigenous species: impact of spatial pattern and developmental stage. Plant Ecol 180:153-160

Bole JB, Allan JR (1978) Uptake of phosphorus from sediment by aquatic plants, Myriophyllum spicatum and Hydrilla verticillata. Water Res 12:353-358

Bristow JM, Whitcombe M (1971) The role of roots in the nutrition of aquatic vascular plants. Am J Bot 58:8-13

> Carignan R, Kalff J (1980) Phosphorus sources for aquatic weeds: Water or sediments? Science 207:987-989

Chen RL, Barko JW (1988) Effects of freshwater macrophytes on sediment chemistry. J Freshw Ecol 4:279-289

> Cook CDK, Urmi-König K (1985) A revision of the genus Elodea (Hydrocharitaceae). Aquat Bot 21:111-156

De Busk TA, Peterson JE, Reddy KR (1995) Use of aquatic and terrestrial plants for removing phosphorus from dairy wastewaters. Ecol Eng 5:371-390

> DeMarte JA, Hartman RT (1974) Studies on absorption of ${ }^{33} \mathrm{P}$, ${ }^{59} \mathrm{Fe}$, and ${ }^{45} \mathrm{Ca}$ by water-milfoil (Myriophyllum exalbescens Fernald). Ecology 55:188-194

Denny P (1972) Sites of nutrient absorption in aquatic macrophytes. J Ecol 60:819-829

Eugelink AH (1998) Phosphorus uptake and active growth of Elodea canadensis Michx. and Elodea nuttallii (Planch.) St. John. Water Sci Technol 37:59-65

Frank PA, Hodgson RH (1964) A technique for studying absorption and translocation in submersed plants. Weeds $12: 80-82$

Gentner SR (1977) Uptake and transport of iron and phosphate by Vallisneria spiralis L. Aquat Bot 3:267-272

Gerloff GC, Krombholz PH (1966) Tissue analysis as a measure of nutrient availability for the growth of angiosperm aquatic plants. Limnol Oceanogr 11:529-537

Gessner F, Kaukal A (1952) Die Ionen-Aufnahme submerser Wasserpflanzen in ihrer Abhängigkeit von der Konzentration der Nährlösung. Ber Dtsch Bot Ges 65:155-163
Granéli W, Solander D (1988) Influence of aquatic macrophytes on phosphorus cycling in lakes. Hydrobiologia 170:245-266

Hadad HR, Maine MA (2007) Phosphorus amount in floating and rooted macrophytes growing in wetlands from the Middle Paraná River floodplain (Argentina). Ecol Eng 31:251-258

Ingold CT (1936) The effect of light on the absorption of salt by Elodea canadensis. New Phytol 35:132-141

Jeschke WD, Simonis W (1965) Über die Aufnahme von Phosphat- und Sulfationen durch Blätter von Elodea densa und ihre Beeinflussung durch Licht, Temperatur und Aussenkonzentration. Planta 67:6-32

Laskov C, Herzog C, Lewandowski J, Hupfer M (2007) Miniaturized photochemical methods for the rapid analysis of phosphate, ammonium, ferrous iron, and sulphate in pore water of freshwater sediments. Limnol Oceanogr Methods 4:63-71

- Madsen TV, Cedergreen N (2002) Sources of nutrients to rooted submerged macrophytes growing in a nutrient-rich stream. Freshw Biol 47:283-291

McRoy CP, Barsdate RJ (1970) Phosphate absorption in eelgrass. Limnol Oceanogr 15:6-13

> Nagasaka M (2004) Changes in biomass and spatial distribution of Elodea nuttallii (Planch.) St. John, an invasive submerged plant, in oligomesotrophic Lake Kizaki from 1999 to 2002. Limnology 5:129-139

> Nino FD, Thiébaut G, Muller S (2005) Response of Elodea nuttallii (Planch.) H. St. John to manual harvesting in the north-east of France. Hydrobiologia 551:147-157

> Ozimek T, Van Donk E, Gulati RD (1993) Growth and nutrient uptake by two species of Elodea in experimental conditions and their role in nutrient accumulation in a macrophytedominated lake. Hydrobiologia 251:13-18

Peltier WH, Welch EB (1969) Factors affecting growth of rooted aquatics in a river. Weed Sci 17:412-416

Pelton DK, Levine SN, Braner M (1998) Measurements of phosphorus uptake by macrophytes and epiphytes from the LaPlatte river (VT) using ${ }^{33} \mathrm{P}$ in stream microcosms. Freshw Biol 39:285-299

Robach F, Hajnsek I, Eglin I, Tremolieres M (1995) Phosphorus sources for aquatic macrophytes in running waters: water or sediment? Acta Bot Gallica 142:719-731

Shardendu B, Ambasht RS (1991) Relationship of nutrient in water with biomass and nutrient accumulation of submerged macrophytes of a tropical wetland. New Phytol 117:493-500

Simpson DA (1984) A short history of the introduction and spread of Elodea Michx in the British Isles. Watsonia 15:1-9

Simpson DA (1990) Displacement of Elodea canadensis Michx by Elodea nuttallii (Planch.) H. St. John in the British Isles. Watsonia 18:173-177

Thiébaut G, Muller S (1999) A macrophyte communities sequence as an indicator of eutrophication and acidification level in weakly mineralised streams in north-eastern France. Hydrobiologia 410:17-24

Thiébaut G, Rolland T, Robach F, Tremolieres M, Muller S (1997) Some consequences of the introduction of two macrophyte species, Elodea canadensis Michaux and Elodea nuttallii St. John, in continental aquatic ecosystems: example of two areas in the north-east of France: Alsace plain and northern Voges. Bull Fr Peche Piscicult 344/345:441-452

Twilley RR, Brinson MM, Davis GJ (1977) Phosphorus absorption, translocation, and secretion in Nuphur luteum. Limnol Oceanogr 22:1022-1032

Welsh RPH, Denny P (1979) The translocation of ${ }^{32} \mathrm{P}$ in two submerged aquatic angiosperm species. New Phytol 82: 645-656

Xie Y, Deng W, Wang J (2007) Growth and root distribution of Vallisneria natans under heterogeneous sediment environments. Aquat Bot 86:9-13

Submitted: November 27, 2007; Accepted: June 24, 2008

Proofs received from author(s): August 11, 2008 